\title{
Generation and detection of 2.56 Tbit/s OTDM data using DPSK and polarisation multiplexing
}

Galili, Michael; Mulvad, Hans Christian Hansen; Oxenløwe, Leif Katsuo; Hu, Hao; Palushani, Evarist; Clausen, Anders; Jeppesen, Palle

Published in:

2010 Conference on (OFC/NFOEC) Optical Fiber Communication (OFC), collocated National Fiber Optic Engineers Conference

Publication date:

2010

Document Version

Publisher's PDF, also known as Version of record

Link back to DTU Orbit

Citation (APA):

Galili, M., Mulvad, H. C. H., Oxenløwe, L. K., Hu, H., Palushani, E., Clausen, A., \& Jeppesen, P. (2010).

Generation and detection of 2.56 Tbit/s OTDM data using DPSK and polarisation multiplexing. In 2010

Conference on (OFC/NFOEC) Optical Fiber Communication (OFC), collocated National Fiber Optic Engineers Conference (pp. 1-3). IEEE.

\section{General rights}

Copyright and moral rights for the publications made accessible in the public portal are retained by the authors and/or other copyright owners and it is a condition of accessing publications that users recognise and abide by the legal requirements associated with these rights.

- Users may download and print one copy of any publication from the public portal for the purpose of private study or research.

- You may not further distribute the material or use it for any profit-making activity or commercial gain

- You may freely distribute the URL identifying the publication in the public portal 


\title{
Generation and Detection of 2.56 Tbit/s OTDM Data using DPSK and Polarisation Multiplexing
}

\author{
M. Galili*, H.C. Hansen Mulvad, L.K. Oxenløwe, H. Hu, E. Palushani, A.T. Clausen, P. Jeppesen \\ DTU Fotonik, Technical University of Denmark, Building 343, Lyngby, Denmark*mgal@fotonik.dtu.dk
}

\begin{abstract}
Error free and low penalty generation and detection of $2.56 \mathrm{Tbit} / \mathrm{s}$ serial data is demonstrated. 1.28 Tbaud pulses are modulated with DPSK and polarisation multiplexed to achieve $2.56 \mathrm{Tbit} / \mathrm{s}$ with record low penalty.

(C) 2010 Optical Society of America

OCIS codes: (060.4370) Nonlinear optics, fibers; (060.2330) Fiber optics communications
\end{abstract}

\section{Introduction}

In recent years there has been an increasing interest in identifying schemes for optical data transmission which can supplement or substitute the schemes currently used in optical communication systems. This is done in the pursuit of higher data capacity and lower power consumption. Optical Time Division Multiplexing (OTDM) is one of the technologies which might potentially offer both of these benefits for many applications [1].

OTDM enables symbol rates beyond $640 \mathrm{Gbaud}$, and can be used with polarisation multiplexing (pol-mux) to generate a serial binary data rate of e.g. $1.28 \mathrm{Tbit} / \mathrm{s}$ [2]. To further increase the data rate in a single wavelength channel, modulation formats enabling several bits per symbol have been used in combination with OTDM and polmux. This strategy has led to a few demonstrations of single channel bit rates of $2.56 \mathrm{Tbit} / \mathrm{s}$ or more. The first demonstration used DQPSK and pol-mux of 640 Gbaud to achieve a bit rate of $2.56 \mathrm{Tbit} / \mathrm{s}$ [3]. Recently by changing the modulation format to 8PSK combined with coherent detection an error free data rate of $3.56 \mathrm{Tbit} / \mathrm{s}$ was demonstrated, assuming UFEC [4]. Finally, using DQPSK and pol-mux at a symbol rate of 1.28 Tbaud an error free bit rate of $5.1 \mathrm{Tbit} / \mathrm{s}$ in a single wavelength channel was achieved in [5].

In this paper, we investigate the performance of 1.28 Tbaud pulses using binary modulation (DPSK) and polmux to achieve $2.56 \mathrm{Tbit} / \mathrm{s}$ with record low penalty. We demonstrate generation and detection of $2.56 \mathrm{Tbit} / \mathrm{s}$ with error free performance $\left(\mathrm{BER}<10^{-9}\right)$ and a total penalty in receiver sensitivity of no more than $3 \mathrm{~dB}$ compared to the original $10 \mathrm{Gbit} / \mathrm{s}$ reference. This is the best performance and lowest penalty ever achieved in a single channel signal reaching more than $2 \mathrm{Tbit} / \mathrm{s}$.

\section{Principle and experimental procedure}

The experimental set-up is shown in Fig. 1. The $2.56 \mathrm{Tbit} / \mathrm{s}$ OTDM transmitter is based on an Erbium-glass oscillator mode locked laser (ERGO), emitting a $10 \mathrm{GHz}$ optical pulse train at $1542 \mathrm{~nm}$ with $1.5 \mathrm{ps}$ FWHM. The optical pulses are spectrally broadened in a dispersion-flattened highly non-linear fibre (DF-HNLF1, $400 \mathrm{~m}$ with $\gamma \sim 10.5 \mathrm{~W}^{-1} \mathrm{~km}^{-1}$, dispersion $\mathrm{D}=-0.45 \mathrm{ps} /(\mathrm{nm} \mathrm{km})$ and slope $\mathrm{S}=0.0057 \mathrm{ps} /\left(\mathrm{nm}^{2} \mathrm{~km}\right)$ at $\left.1550 \mathrm{~nm}\right)$ and subsequently filtered by a $5 \mathrm{~nm}$ band-pass filter (BPF) centred at $1550 \mathrm{~nm}$. The optical spectra after broadening in DF-HNLF1 and after the $5 \mathrm{~nm}$ BPF are shown in Fig. 2a. The offset filtering effectively increases the contrast in the pulse train by suppressing undesired components present in the ERGO output. The output from the first compression stage is

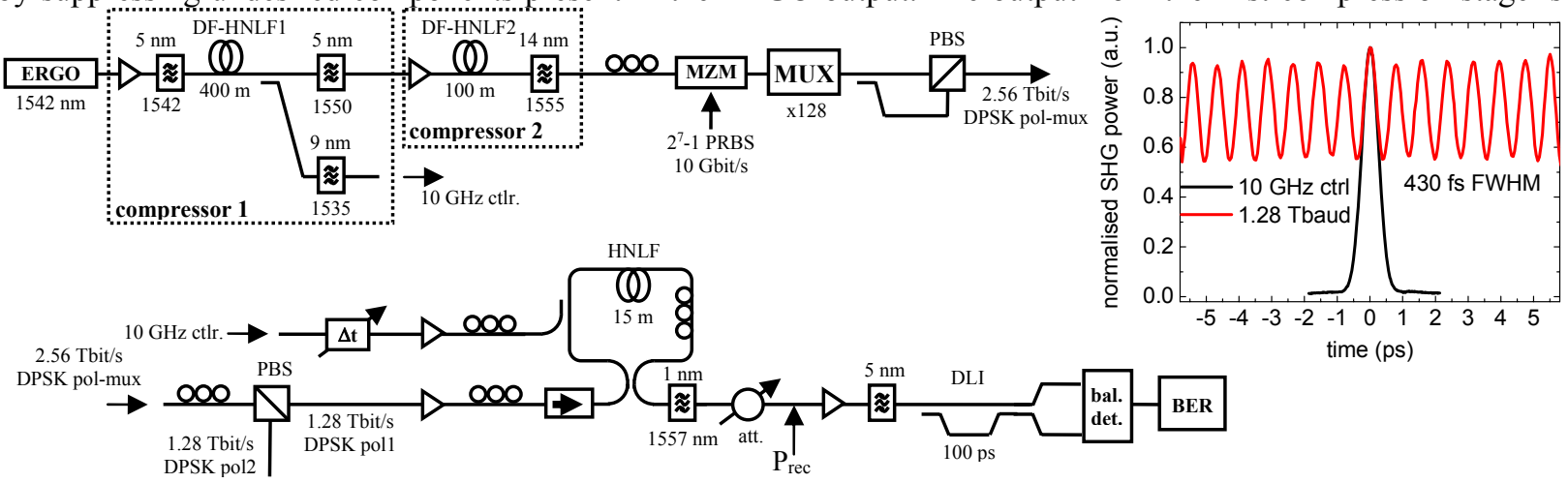

Fig. 1: Setup for generating and detecting 2.56 Tbit/s DPSK pol-mux. Autocorrelation shows multiplexed data pulses at $1.28 \mathrm{Tbaud}$ and $10 \mathrm{GHz}$ control pulses used demultiplexing. 


\section{OThV2.pdf}

also used to generate the $10 \mathrm{GHz}$ control pulses (ctrl) to be used for demultiplexing. These are extracted using a $9 \mathrm{~nm}$ BPF centred at $1535 \mathrm{~nm}$. The pulse train at $1550 \mathrm{~nm}$ is further compressed by spectral broadening in DFHNLF2 $\left(100 \mathrm{~m}\right.$ with $\gamma \sim 10.5 \mathrm{~W}^{-1} \mathrm{~km}^{-1}, \mathrm{D}=-1.06 \mathrm{ps} /(\mathrm{nm} \mathrm{km})$ and $\left.\mathrm{S}=0.004 \mathrm{ps} /\left(\mathrm{nm}^{2} \mathrm{~km}\right)\right)$ and filtering with a $14 \mathrm{~nm}$ BPF at $1555 \mathrm{~nm}$. The optical spectra after broadening in DF-HNLF2 and after the $14 \mathrm{~nm}$ BPF are shown in Fig. $2 \mathrm{~b}$. The compressed pulses are then data modulated with $10 \mathrm{Gbit} / \mathrm{s}$ DPSK data using a chirp free Mach-Zehnder modulator (MZM) encoding a $2^{7}-1$ PRBS pattern. The data pulses are then OTDM-multiplexed from $10 \mathrm{Gbit} / \mathrm{s}$ up to $1.28 \mathrm{Tbit} / \mathrm{s}$ in a PRBS maintaining multiplexer (MUX) based on passive fibre delay lines. The autocorrelation in Fig. 1 shows that the multiplexing is performed with virtually no variation between the OTDM tributaries. Finally, the 1.28 Tbit/s DPSK signal is polarisation multiplexed (POL-MUX) by splitting the signal in a $3 \mathrm{~dB}$ coupler and combining the two outputs in a polarisation beam splitter (PBS). This results in a polarisation multiplexed $2.56 \mathrm{Tbit} / \mathrm{s}$ data signal. In this back-to-back demonstration the $2.56 \mathrm{Tbit} / \mathrm{s}$ data signal is then detected in the receiver setup as shown in the lower part of Fig. 1. Firstly, the PBS separates the two $1.28 \mathrm{Tbit} / \mathrm{s}$ polarisation components (pol1 and pol2) of the incoming $2.56 \mathrm{Tbit} / \mathrm{s}$ pol-mux data. A nonlinear optical loop mirror (NOLM) is then used to demultiplex the $1.28 \mathrm{Tbit} / \mathrm{s}$ data down to the individual $10 \mathrm{Gbit} / \mathrm{s}$ tributary channels. The NOLM operation is based on cross-phase modulation in a $15 \mathrm{~m} \operatorname{HNLF}\left(\gamma \sim 10.5 \mathrm{~W}^{-1} \mathrm{~km}^{-1}\right.$, zero-dispersion wavelength $\lambda_{0} \sim 1545 \mathrm{~nm}$ and $\left.\mathrm{S}=0.015 \mathrm{ps} /\left(\mathrm{nm}^{2} \mathrm{~km}\right)\right)$ using the $10 \mathrm{GHz}$ ctrl pulses at $1535 \mathrm{~nm}$. The optical spectra of the data and control pulses in the NOLM are shown in Fig. 2c. The demultiplexed $10 \mathrm{Gbit} / \mathrm{s}$ signal is extracted using a $1 \mathrm{~nm}$ BPF at $1557 \mathrm{~nm}$ to suppress the control pulses (c.f. Fig. 2c), and finally detected using a $10 \mathrm{Gbit} / \mathrm{s}$ DPSK receiver. Here, the $10 \mathrm{Gbit} / \mathrm{s}$ DQPSK data are preamplified, filtered and then demodulated using a 1-symbol delay interferometer (DLI). The DLI output is detected using a balanced photo-detector, and then injected into a $10 \mathrm{Gbit} / \mathrm{s}$ error-detector for bit error rate (BER) evaluation.
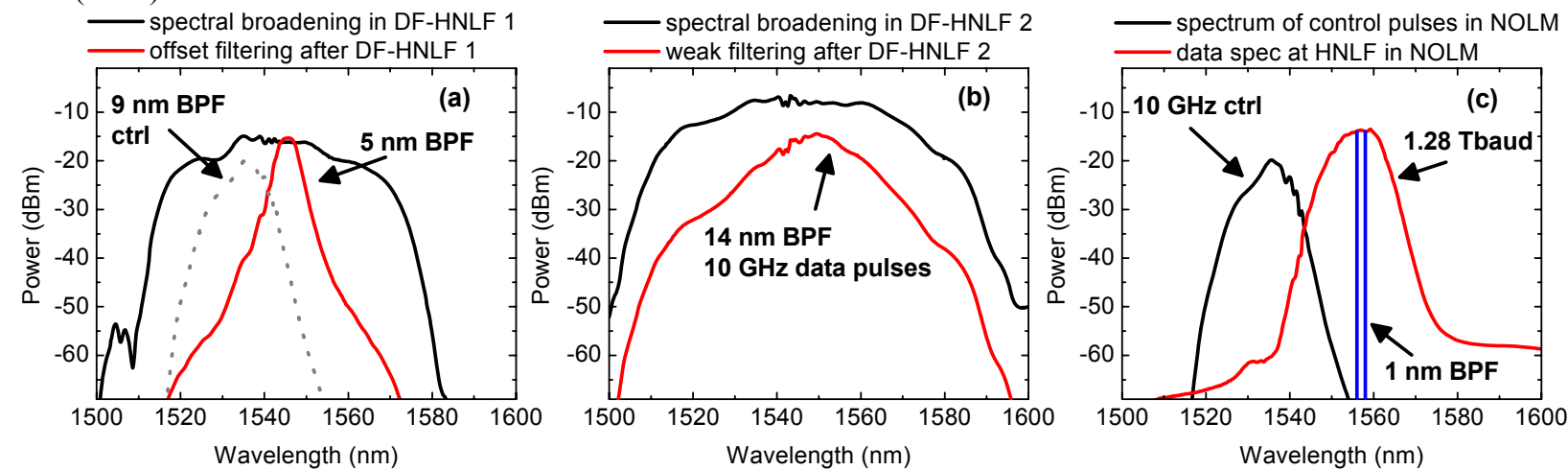

Fig. 2: (a) Spectral broadening in DF-HNLF 1 and subsequent offset filtering. (b) Spectral broadening in DF-HNLF 2 and subsequent slight spectral shaping by $14 \mathrm{~nm}$ filter. (c) Data spectrum in NOLM after shaping in EDFAs and control pulses used for demultiplexing.

\section{Results and discussion}

Fig. 2. shows optical spectra describing the key optical processing required in order to create and detect the 1.28 Tbaud pulses used in this demonstration. In Fig. 2a the operation of the first compression stage is shown. The key function of this stage is to suppress trailing pulses emitted by the ERGO laser and at the same time compress the pulses to less than 1 ps FWHM. In this way an optimised input to the final compression stage is extracted from the broadened spectrum using a $5 \mathrm{~nm}$ BPF centred $8 \mathrm{~nm}$ away from the original ERGO output. The first compression stage is also used to generate the demux control pulses at $1535 \mathrm{~nm}$. These are extracted with a $9 \mathrm{~nm}$ BPF generating pulses of $\sim 430 \mathrm{fs}$ FWHM which is close to the target pulse width for the data pulses, however, the control pulses have insufficient suppression of the trailing pulses to allow stable multiplexing. Fig. $2 \mathrm{~b}$ shows the spectral broadening and filtering in the second compression stage. The output is filtered broad enough to allow significant spectral shaping by the EDFAs used to compensate the loss throughout the rest of the setup. The spectrum of the data pulses in the NOLM demultiplexer corresponding to the autocorrelation in Fig. 1 is shown in Fig. 2c. For this spectrum of the data pulse a pulse width of $\sim 410 \mathrm{fs}$ FWHM is measured giving a time bandwidth product (TBP) of $\sim 0.5$ for the data pulses in the demultiplexer. This is only $14 \%$ above the transform limit for a Gaussian pulse. It is expected that this low TBP can be achieved for the data pulses throughout the setup if gain flattened EDFAs were used instead of the standard EDFAs that were available for this demonstration. Fig. 2c also shows the wavelength allocation of control and data signals in the demultiplexer where a $1 \mathrm{~nm}$ BPF is used to suppress the control pulses at the output by selecting a part of the data spectrum which does not overlap with the control pulses. 


\section{OThV2.pdf}

Fig. 3 shows the BER results for both the $1.28 \mathrm{Tbit} / \mathrm{s}$ DPSK signal and for the polarisation multiplexed signal achieving $2.56 \mathrm{Tbit} / \mathrm{s}$. In both cases eight consecutive OTDM channels were measured in order to estimate the variation in performance between the multiplexed channels. The $10 \mathrm{Gbit} / \mathrm{s}$ reference signal is measured by launching the output of the MZM into the DPSK receiver and thus bypassing both the multiplexer and demultiplexer. The eye diagram (a) in Fig. 3 shows the clear and open eye of the $10 \mathrm{Gbit} / \mathrm{s}$ reference signal which is confirmed by a receiver sensitivity of $\sim-41 \mathrm{dBm}$ at a BER of $10^{-9}$. For the single polarisation $1.28 \mathrm{Tbit} / \mathrm{s}$ signal the eight channels have a variation in receiver sensitivity of only $0.5 \mathrm{~dB}$ and they have an average penalty of $2.5 \mathrm{~dB}$ compared to the $10 \mathrm{Gbit} / \mathrm{s}$ reference. For the polarisation multiplexed $2.56 \mathrm{Tbit} / \mathrm{s}$ signal BER curves for eight channels in each polarisation are shown with corresponding eye diagrams in Fig. 3 (b) and (c). The performance of the signal is almost unchanged by the polarisation multiplexing resulting in $0.2 \mathrm{~dB}$ excess penalty in one polarisation and $0.5 \mathrm{~dB}$ in the other and a slight increase in channel variation in one polarisation. For all detected signals and channels there is no indication of an error floor down to a BER of at least $10^{-10}$. The $2.5 \mathrm{~dB}$ to $3 \mathrm{~dB}$ penalty in receiver sensitivities is attributed mainly to reduced OSNR caused by the EDFAs in the setup. To reduce this penalty the losses in the setup for generating and detecting the signal will have to be reduced.
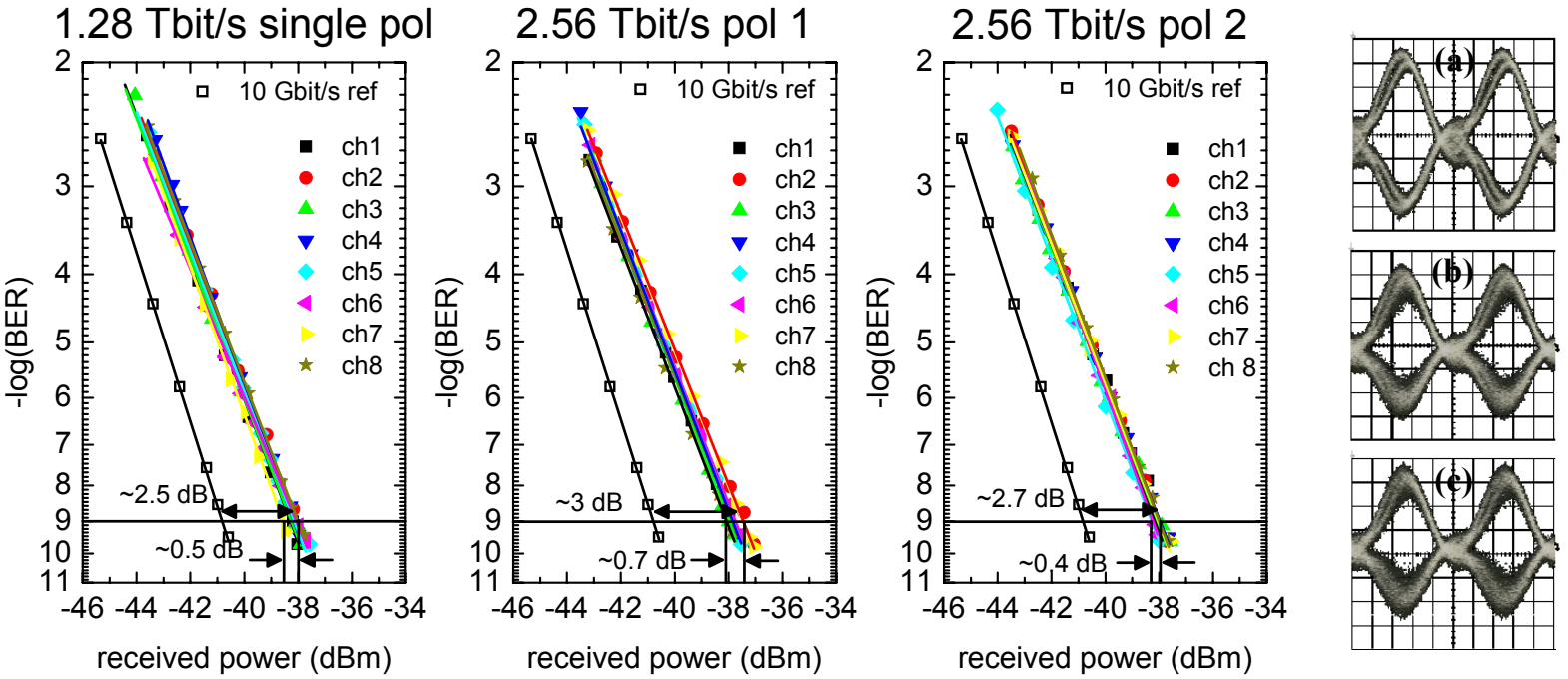

Fig. 3: Bit error rate results for 8 consecutive channels for both the single polarisation $1.28 \mathrm{Tbit} / \mathrm{s}$ signal and for each polarisation in the polarisation multiplexed 2.56 Tbit/s signal. (a) $10 \mathrm{Gbit} / \mathrm{s}$ reference after demodulation and differential detection. (b) Pol 1 of $2.56 \mathrm{Tbit} / \mathrm{s}$ after 4. Conclusion demux. (c) Pol 2 of $2.56 \mathrm{Tbit} / \mathrm{s}$ after demux.

We have demonstrated error free and low penalty generation and detection of a $2.56 \mathrm{Tbit} / \mathrm{s}$ DPSK pol-mux signal in a single wavelength channel. All the detected signals achieve a BER $<10^{-9}$ and exhibit no sign of an error floor. We achieve less than $1 \mathrm{~dB}$ variation in receiver sensitivity between the measured OTDM channels and less than $3 \mathrm{~dB}$ penalty compared to the $10 \mathrm{Gbit} / \mathrm{s}$ reference signal. This constitutes the best performance and lowest penalty ever achieved in a single channel signal reaching more than $2 \mathrm{Tbit} / \mathrm{s}$. This demonstration makes clear that low penalty generation and detection of single channel data signals of several Tbit/s is feasible using a high symbol rate and simple modulation format.

\section{Acknowledgments}

This work is supported by Danish NABIIT grant 2106-06-0052, project Nano-com.

All HNLF is kindly provided by OFS Fitel Denmark Aps.

\section{References}

[1] T. Asami et al, "Energy Consumption Targets for Network Systems," in Proc. ECOC'08, Tu.4A.3 (2008).

[2] M. Nakazawa et al, "1.28 Tbit/s-70 km OTDM transmission using third- and fourth-order simultaneous dispersion compensation with a phase modulator," Electron. Lett., 36 (24), pp 2027-2029, (2000).

[3] H.G. Weber et al, "Single channel 1.28 Tbit/s and 2.56 Tbit/s DQPSK transmission," Electron.Lett., 42 (3), pp 178-179, (2006).

[4] C. Schmidt-Langhorst et al, "Generation and Coherent Time-Division Demultiplexing of up to $5.1 \mathrm{~Tb} / \mathrm{s}$ Single-Channel 8-PSK and 16-QAM Signals," Proc. OFC'09, paper PDPC6, (2009).

[5] H. C. Hansen Mulvad et al, "Error-Free 5.1 Tbit/s Data on a Single-Wavelength Channel Using a 1.28 Tbaud Symbol Rate," in Proc. IEEE Photonics Society, PD 1.2 (2009). 